\title{
ВЫСОКОСКОРОСТНОЙ ПИРОЛИЗ МОДЕЛЬНЫХ СМЕСЕЙ ДИКТИОНЕМОВОГО СЛАНЦА ЭСТОНСКОЙ ССР (КОНЦЕНТРАТА) С ГЛИНИСТЫМИ ОСТАТКАМИ ЕГО ОБОГАЩЕНИЯ
}

\author{
(Представил О. Эйзен)
}

В $\left[{ }^{1,2}\right]$ исследовали скоростной пиролиз канско-ачинского бурого угля и кукерсита. В настоящей работе пиролизу подвергали три модельные смеси концентрата диктионемового сланца ЭССР (месторождения Тоол-

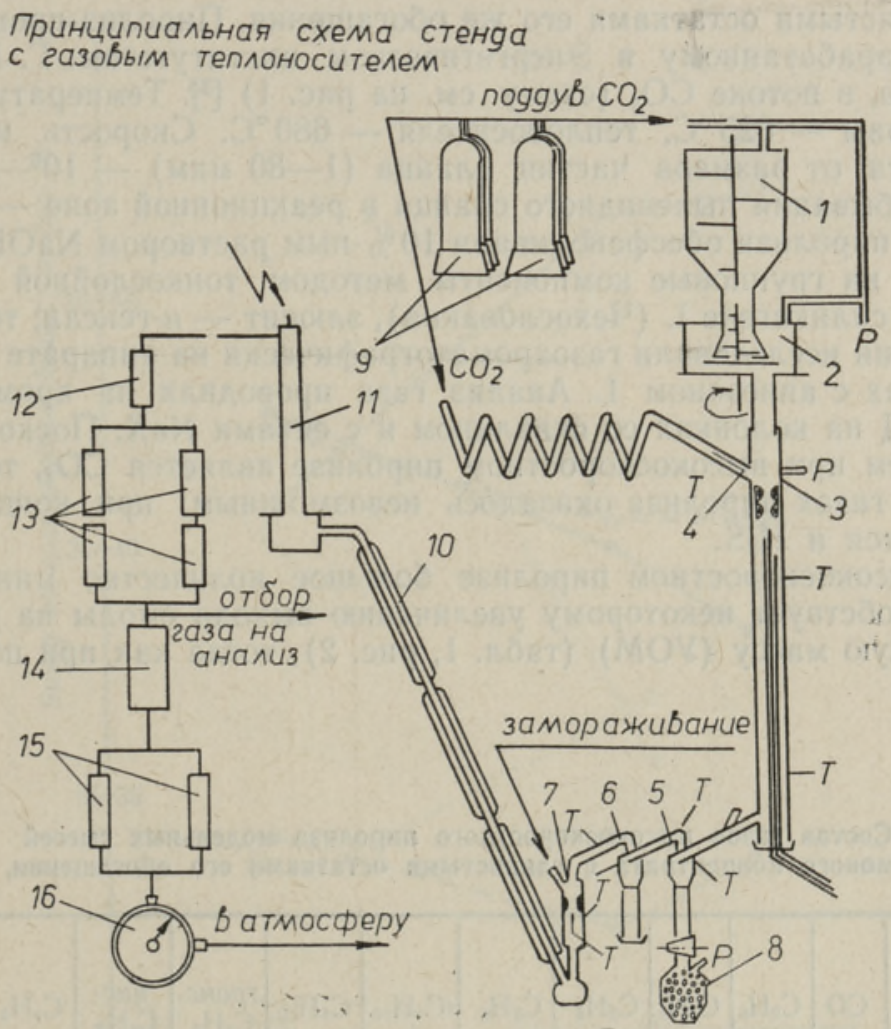

Рис. 1. Прннципиальная схема стенда с газовым теплоносителем. Условные обозначения: 1 - бункер топлива, 2 - питатель топлива, 3 - реактор, $4-$ электронагреватель теплоносителя, 5 - сепаратор, 6 - циклон, 7 - замораживатель, 8 - приемный бункер коксика, 9 - рессивер теплоносителя, 10 - система холодильников, 11 - электрофильтр, 12 - ватный фнльтр, 13 - патрон с $\mathrm{CaCl}_{2}, 14$ - патрон с болотной рудой, 15 - адсорберы с активированным углем, 16 - газовые часы, $P \ldots P-$ точки замера давления, Т... T - точки замера температуры. 
Характеристика исходных смесей и выход продуктов высокоскоростного пиролиза модельных смесей концентрата диктионемового сланца с глинистыми остатками его обогащения

\begin{tabular}{|c|c|c|c|}
\hline \multirow[b]{2}{*}{ Показатели } & \multicolumn{3}{|c|}{ Номер образца } \\
\hline & 1 & 2 & 3 \\
\hline $\begin{array}{l}\text { Влага аналитическая } W a \\
\text { Зольность } A d \\
\text { Условная органическая масса } \\
\text { УОМ =(100-Ad)* } \\
\text { Выход продуктов пиролиза на } \\
\text { сухой сланец, вес. \%: } \\
\text { вода разложения } \\
\text { смола } \\
\text { твердый остаток } \\
\text { газ }\end{array}$ & $\begin{array}{r}1,4 \\
80,5 \\
19,5\end{array}$ & $\begin{array}{r}3,4 \\
52,8 \\
47,2 \\
\\
9,5 \\
10,3 \\
78,2 \\
2,0\end{array}$ & $\begin{array}{r}9,8 \\
12,9 \\
73,0 \\
4,3\end{array}$ \\
\hline
\end{tabular}

* $\left(\mathrm{CO}_{2}\right)_{M}$ отсутствует.

се) с глинистыми остатками его же обогащения. Пиролиз проводили по методу, разработанному в Энергетическом институте им. Г. М. Кржижановского, в потоке $\mathrm{CO}_{2}$ (схему см. на рис. 1) [3]. Температура реакционной зоны $-625^{\circ} \mathrm{C}$, теплоносителя $-680^{\circ} \mathrm{C}$. Скорость нагрева в зависимости от размера частиц сланца $(1-80$ мкм $)-10^{6}-10^{4} \%$ мин. Время пребывания пылевидного сланца в реакционной зоне $-0,25 \mathrm{c}$.

Смолы пиролиза обесфеноливали $10 \%$-ным раствором $\mathrm{NaOH}$ и затем разделяли на групповые компоненты методом тонкослойной хроматографии на силикагеле L (Чехословакия), элюент - -гексан; тонкослойные фракции исследовали газохроматографически на аппарате «Хром-4» на колонках с апиезоном L. Анализ газа проводили на хроматографе ЛХМ-8-МД на колонках со скваланом и с ситами $\mathrm{NaX}$. Поскольку теплоносителем при высокоскоростном пиролизе является $\mathrm{CO}_{2}$, то определить его в газах пиролиза оказалось невозможным; при концентрации газа теряется и $\mathrm{H}_{2} \mathrm{~S}$.

При высокоскоростном пиролизе большое количество минеральной части способствует некоторому увеличению выхода смолы на условную органическую массу (УОМ) (табл. 1, рис. 2), тогда как при полукоксо-

Tаблича 2

Состав газов высокоскоростного пиролиза модельных смесей диктионемового концентрата с глинистыми остатками его обогащения, об. \%

\begin{tabular}{|c|c|c|c|c|c|c|c|c|c|c|c|c|c|}
\hline 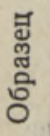 & $\mathrm{H}_{2}$ & $\mathrm{CH}_{4}$ & $\mathrm{CO}$ & $\mathrm{C}_{2} \mathrm{H}_{6}$ & $\mathrm{C}_{2} \mathrm{H}_{4}$ & $\mathrm{C}_{3} \mathrm{H}_{8}$ & $\mathrm{C}_{3} \mathrm{H}_{6}$ & $i \mathrm{C}_{4} \mathrm{H}_{10}$ & $\mathrm{C}_{4} \mathrm{H}_{10}$ & $\begin{array}{l}\text { транс- } \\
\mathrm{C}_{4} \mathrm{H}_{8}\end{array}$ & $\begin{array}{c}\mu u c- \\
\mathrm{C}_{4} \mathrm{H}_{8}\end{array}$ & $\mathrm{C}_{4} \mathrm{H}_{6}$ & $\frac{C_{n} H_{2 n+2}}{\mathrm{C}_{n} \mathrm{H}_{2 n}}$ \\
\hline 1 & 10,0 & 13,4 & 66,9 & 2,0 & 3,7 & 0,6 & 2,0 & - & 0,4 & 0,8 & 0,2 & - & 2,44 \\
\hline 2 & 13,4 & 17,2 & 57,4 & 2,6 & 4,4 & 0,8 & 2,2 & - & 0,4 & 0,7 & 0,9 & - & 2,55 \\
\hline 3 & 13,5 & 22,8 & 48,0 & 3,3 & 5,8 & 1,0 & 2,9 & 0,1 & 0,4 & 0,8 & 0,6 & 0,8 & 2,38 \\
\hline
\end{tabular}


вании подобных модельных смесей в стандартных условиях наблюдается обратная картина - снижение выхода смолы на УОМ [3] за счет адсорбции части смолы на минеральной матрице и ее дополнительного крекинга, т. е. за счет вторичных реакций. При высокоскоростном пиролизе время пребывания образующейся смолы в зоне реакции настолько мало, что вторичные процессы подавляются, и на первый план выступает благоприятствующий смолообразованию каталитический эффект глинистой минеральной матрицы сланца.

Возрастание выхода пирогенетической воды с повышением содержания в образце минеральных веществ (рис. 2, кривая 3 ) можно объяснить выделением кристаллической воды алюмосиликатов, содержащихся в минеральной части.

На меньшее развитие вторичных реакций при скоростном пиролизе указывает и относительно невысокий выход газа $(1,6-4,3 \%)$ на сланец (табл. 1). Хотя содержание основных компонентов газа несколько завышено вследствие потерь $\mathrm{CO}_{2}$ и $\mathrm{H}_{2} \mathrm{~S}$ (табл. 2), прослеживается тенденция к увеличению содержания СО в газах пиролиза из смесей с меньшим содержанием органического вещества (OB) и увеличению содержания водорода с повышением концентрации ОВ в смеси. Обращает на себя внимание, что степень ненасыщенности газообразных углеводородов значительно выше, чем при полукоксовании по ГОСТу 3168-66 [4].

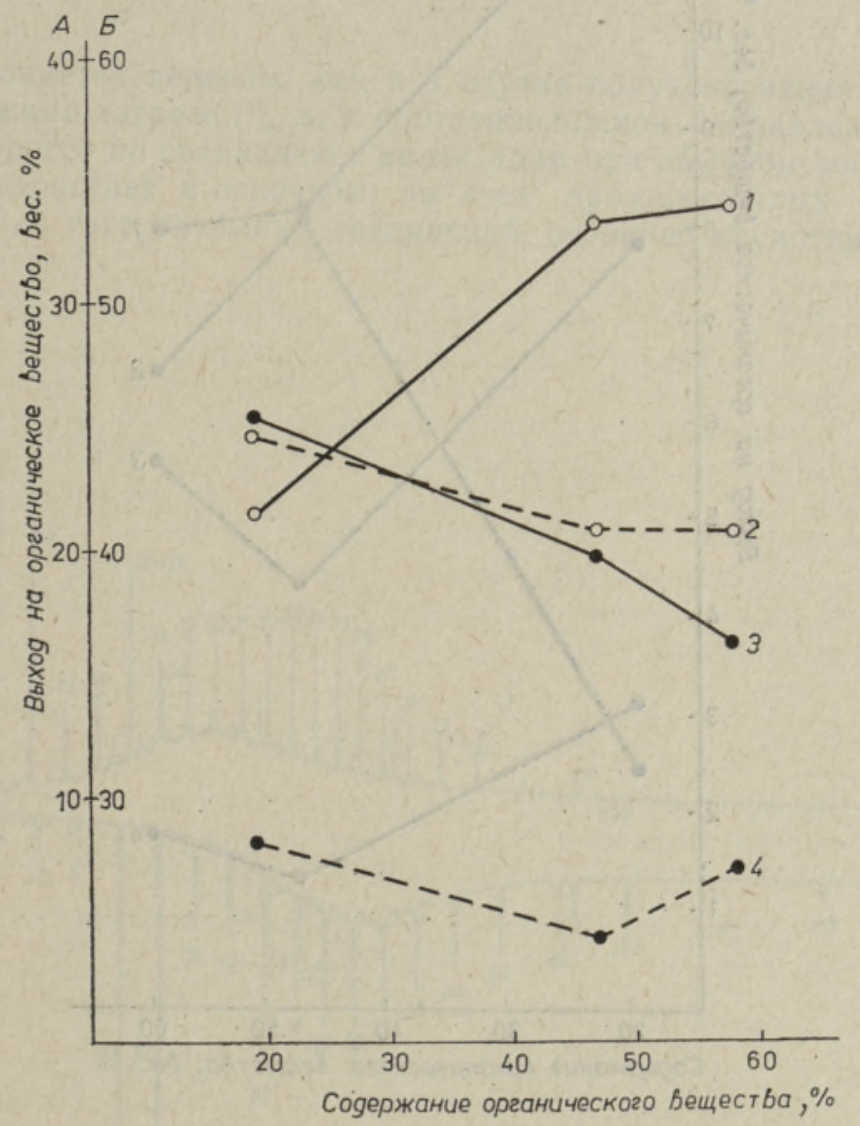

Рис. 2. Зависимость выхода основных продуктов высокоскоростного пиролиза модельных смесей диктионемового сланца с глинистыми остатками его обогащения на органическое вещество от его содержания в смеси: 1 - твердый остаток (шкала Б), 2 - смола (А), 3 - вода разложения (А), 4 - газ (А). 
Смӧлы высобкоскоростного пиролиза модельных смесей (табл. 3) имеют высокую плотность $(>1)$, низкое значение $\mathrm{H} / \mathrm{C}$ (среднее 1,17 ) и обогащены кислородом $(8-10 \%)$, т. е. они более первичны, чем смолы, образующиеся при обычном полукоксовании. С повышением содержания минеральных веществ в смеси подавляется образование фенолов, особенно тяжелых (нерастворимых в эфире), возрастает содержание нейтральных гетероатомных соединений в смоле, что, по-видимому, объясняется активной адсорбцией фенолов как наиболее полярных компонентов смолы на поверхности твердого остатка разложения, чему не может препятствовать и очень быстрая эвакуация парагазовой смеси. В целом, по сравнению со смолой, образующейся при стандартном полукоксовании, смола высокоскоростного пиролиза обогащена гетероатомными соединениями - результат снижения степени дальнейшей деструкции этих относительно термолабильных соединений вследствие малого времени пребывания в горячей зоне. На кривых выхода отдельных компонентов (рис. 3) в расчете на ОВ при его $40-50 \%$-ном содержании в

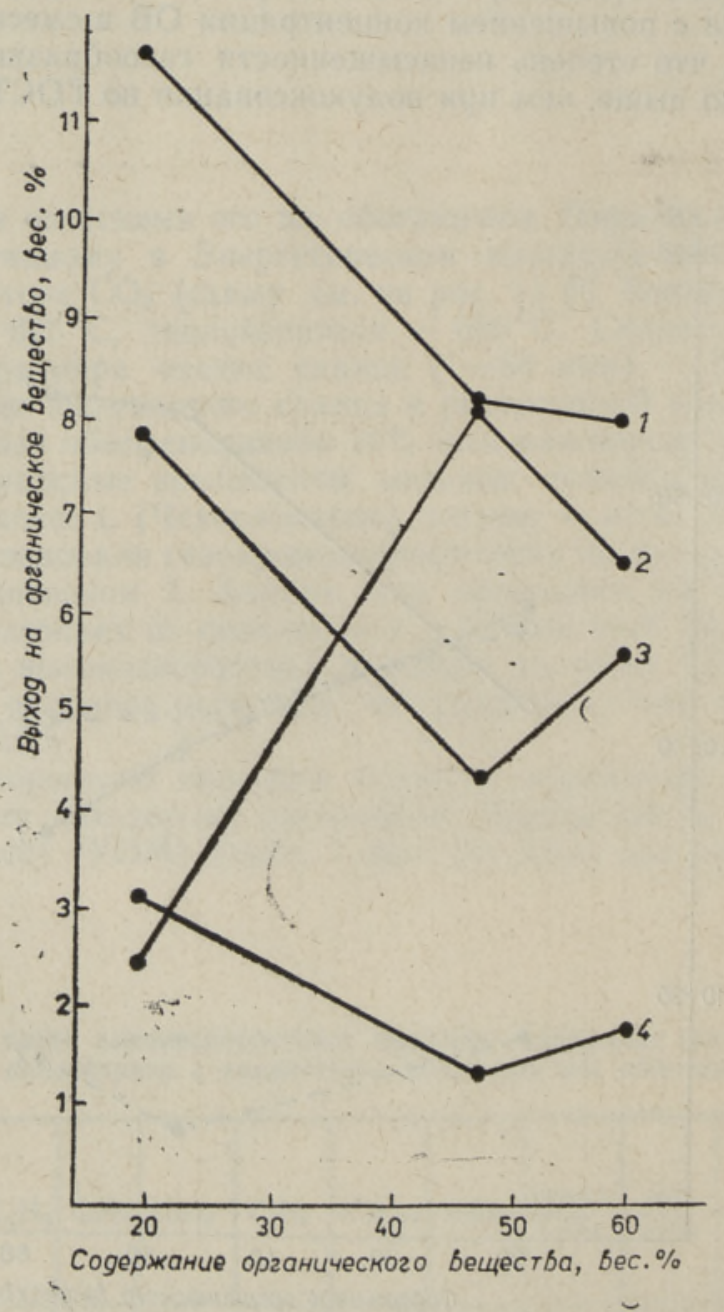

Рис. 3. Зависимость выхода основных групп соединений смол пиролиза модельных смесей концентрата диктионемового сланца с глинистыми остатками его обогащения от содержания органического вещества в смеси: 1 - гетероатомные соединения, 2 - кислотные соединения, 3 - ароматические углеводороды, 4 - неароматические углеводороды. 
Характеристика смол высокоскоростного пиролиза модедьных смесей диктионемового концентрата с глинистыми остатками его обогащения

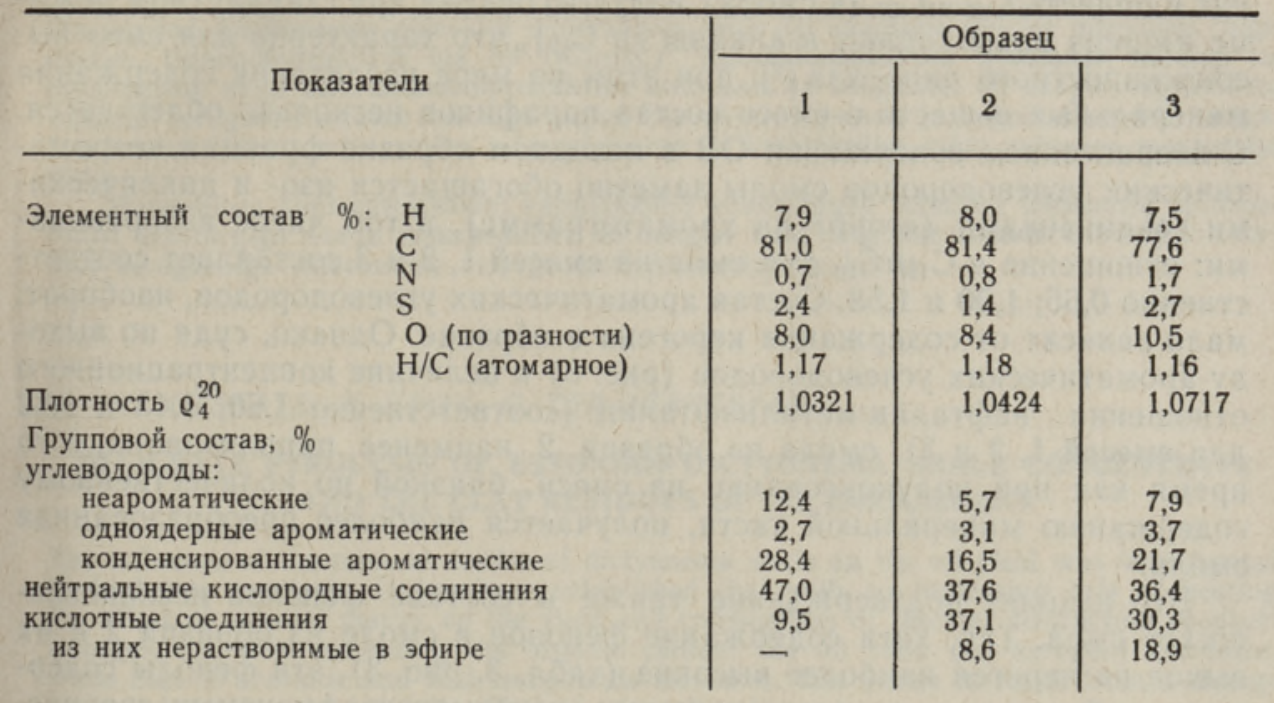

смеси наблюдается перелом, как и в случае полукоксования при стандартном режиме нагрева [ $\left.{ }^{4}\right]$, но в противоположном направлении. Выход смолы на кероген по сравнению с ее выходом при обычном полукоксовании здесь возрастает, в основном, за счет промежуточных продуктов разложения - гетероатомных соединений, особенно кислотных (рис. 3 , кривая 2).

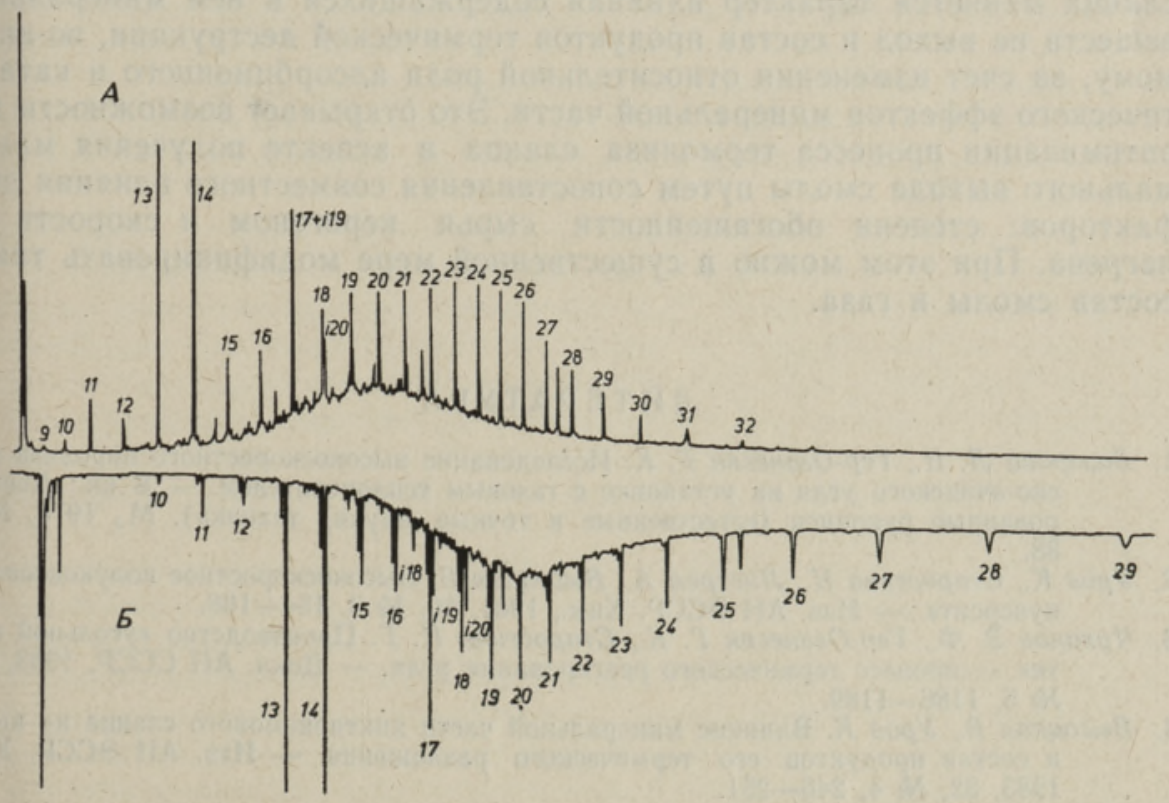

Рис. 4. Хроматограммы неароматических углеводородов смолы полукоксовання модельной смеси 1. Колонки: OV-1701 (A) и SE-30 (Б) с иммобилизованной фазой; кварцевые капиллярные, длина 25 м, диаметр 0,32 мм. Цифры $9-32$ - число атомов углерода в цепи $н$-алкана, 
Анализ методом ГЖХ позволил более подробно охарактеризовать состав образующихся при пиролизе смол. Так, концентрационный максимум содержащихся в исследованных смолах н-алканов (рис. 4) сдвинут в область $\mathrm{C}_{19}-\mathrm{C}_{27}$ (в смолах полукоксования при стандартном режиме нагрева преобладают $\boldsymbol{H}$-алканы до $\mathrm{C}_{17}$ ), что характерно для смол высокоскоростного пиролиза ${ }^{[2]}$; при этом по мере увеличения содержания минеральных веществ в смеси состав парафинов несколько облегчается. C возрастанием содержания ОВ в исходном образце фракция неароматических углеводородов смолы заметно обогащается изо- и циклическими соединениями («горб» на хроматограмме), в том числе изопренанами: отношение $\mu$ - $\mathrm{C}_{18} / i \mathrm{C}_{20}$ для смол из смесей 1,2 и 3 составляет соответственно 0,$65 ; 1,00$ и 1,58 . Состав ароматических углеводородов, наоборот, мало зависит от содержания керогена в образце. Однако, судя по выходу ароматических углеводородов (рис. 3) и величине концентрационного отношения нафталин:метилнафталин (соответственно $1,60,1,43$ и 1,62 для смесей 1,2 и 3), смола из образца 2 наименее пиролизована, в то время как при полукоксовании из смеси, близкой по количественному содержанию минеральной части, получается наиболее преобразованная смола.

Это находит подтверждение также в составе фенолов исследовавшихся смол. Так, хотя содержание фенолов в смоле из образца 2 и их выход на кероген наиболее высокие (табл. 3 , рис. 3), эти фенолы содержат наибольшее количество тяжелых, нехроматографируемых соединений. Состав низкокипящих фенолов, однако, закономерно облегчается по мере обогащения подвергающейся пиролизу смеси OB: концентрационное отношение оксибензол:крезолы для смол из смесей 1,2 и 3 составляет соответственно $0,19,0,22$ и 0,32 .

\section{Заключение}

Из полученных данных следует, что с повышением скорости нагрева сланца меняется характер влияния содержащихся в нем минеральных веществ на выход и состав продуктов термической деструкции, по-видимому, за счет изменения относительной роли адсорбционного и каталитического эффектов минеральной части. Это открывает возможности для оптимизации процесса термолиза сланца в аспекте получения максимального выхода смолы путем сопоставления совместного влияния двух факторов: степени обогащенности сырья керогеном и скорости его нагрева. При этом можно в существенной мере модифицировать также состав смолы и газа.

\section{ЛИ Т Р РА Т РА}

1. Базарова Л. Н., Тер-Оганесян $Г$. К. Исследование высокоскоростного пиролиза канско-ачинского угля на установке с газовым теплоносителем. - В кн.: Депонированные рукописи (естественные и точные науки, техника). М., 1978, № 5, 88.

2. Уров К., Старостина Н., Листрем А., Высоцкая В. Высокоскоростное полукоксование кукерсита. - Изв, АН ЭССР. Хим., 1981, 30, № 3, 154-168.

3. Чуханов 3. Ф., Тер-Оганесян $Г$. К., Старостина Н. Г. Производство жугольной нефти» - процесс термического реагирования угля. - Докл. АН СССР, 1983, 272, № $5,1186-1189$.

4. Высоцкая B., Уров K. Влияние минеральной части диктионемового сланца на выход и состав продуктов его термического разложення. - Изв. АН ЭССР. Хим., 1983,32 , № 4, 246-251.

Институт химии

Академии наук Эстонской ССР 


\section{EESTI NSV DIKTUONEEMA POLEVKIVI KONTSENTRAADI MUDELSEGUDE (KOOS SAMA POLEVKIVI RIKASTAMISE SAVIJÄĂKIDEGA) OLIKIIRE PUROLUUS}

On uuritud diktüoneema põlevkivi mineraalosa mõju õli saagisele ülikiire pürolüüsi tingimustes (kuumutamiskiirus üle $10^{5} \mathrm{OC} / \mathrm{min}$.). Kuumutamiskiiruse muutudes muutub ka mineraalosa mõju destruktsiooniproduktide koostisele ja saagisele: õli saagis orgaanikale väheneb kerogeenisisalduse kasvuga segus, kasvab aromaatsete ja hapnikuühendite saagis. See toimub ilmselt mineraalosa adsorptsioonse ja katalüütilise mõju suhtelise muutumise tôttu.

Mineraalosa kontsentratsiooni variatsioonid võimaldavad termilise töötlemise optimeerimist eesmärgiga saada maksimaalset õli saagist kahe järgmise faktori ühismõjul: tooraine kerogeeniga rikastamise aste ja tema kuumutamise kiirus.

\section{VYSSOTSKAYA, K. UROV, G. TER-OGANESYAN}

\section{HIGH-RATE PYROLYSIS OF ESTONIAN DICTYONEMA SHALE CONCENTRATE AND THE CLAY RESIDUES OF ITS ENRICHMENT}

The influence of the mineral matter of dictyonema shale on the oil yield was investigated by high-rate pyrolysis. It has been established that with an increasing rate of heating the effect of mineral matter on the yield and composition of thermal destruction products changes, i. e. with increasing the organic content the oil yield (on kerogen) decreases, while that of aromatic and acid compounds increases. This seems to result from a change in the adsorptive and catalytic effect of mineral matter.

Variations in the mineral matter concentration permit optimization of the thermolysis process in order to obtain oil in a high yield by combining the effect of two factors, viz. the degree of enrichment of the raw material with kerogen and the rate of heating of the former. The oil and gas composition may also be modified. 